\title{
Capsule Commentary on Alkureishi et al., Impact of Electronic Medical Record Use on the Patient-Doctor Relationship and Communication: A Systematic Review
}

\author{
Michael H. Kanter, MD, CPPS \\ Regional Medical Director of Quality \& Clinical Analysis, Southern California Permanente Medical Group, Pasadena, CA, USA.
}

J Gen Intern Med 31(5):538

DOI: $10.1007 / \mathrm{s} 11606-016-3626-1$

(c) Society of General Internal Medicine 2016

$\mathrm{T}$ he well-performed systematic review by Alkureishi et al. ${ }^{1}$ examined the impact that the use of the electronic medical record (EMR) has on the patient-doctor relationship. Alkureishi et al. reviewed 53 eligible studies from the English literature of studies on EMR use and the patient-doctor relationship and face-to-face communication. Studies either looked at analysis of the behaviors of the patients/physicians or patient perceptions as measured by survey or interview. What the authors found was that although objective studies of communication found some potentially negative behaviors such as interrupted speech, provider multitasking, provider screen gazing, and low rates of screen sharing, most studies found no impact on the patient perceptions of satisfaction. Some studies showed some positive aspects of the EMR that appeared to facilitate clarification, questions, and discussion.

There were obvious limitations in the systematic review due to the heterogeneous nature of the studies, which varied widely in methods, settings, and other factors. Other limitations included exclusion of non-English literature, not considering virtual or non-face-to-face care, few studies of inpatient interactions, and lack of data on how race/ethnicity or age of the patients may impact perceptions.

Many important questions were not in the scope of this review. Frequently, EMRs are linked to communication outside of the office visit using patient portals, email, (telephone or video visits), and Open Notes. Thus, there is a need for more understanding as to how these alternative venues of communication change the entire patient care experience with EMRs. Moreover, it will be important to study what educational or other interventions may increase patient satisfaction with the EMR. There is much physician dissatisfaction with EMRs due to poor useability, ${ }^{2}$ and it is not unreasonable to think that improving physician satisfaction with EMRs may also improve patient satisfaction. Greater work is needed in this important area as well.

Yet, this study is hugely important. Patient satisfaction is widely used as a publicly reported quality metric and for pay for performance programs, ${ }^{3}$ and therefore this study should reassure physicians that they can safely deploy EMRs.

Corresponding Author: Michael H. Kanter, MD, CPPS; Regional Medical Director of Buality Clinical Analysis, Southern California Permanente Medical Group, Pasadena, CA, USA (e-mail: Michael.h.kanter@kp.org).

\section{Compliance with Ethical Standards:}

Conflicts of Interest: Author have no conflict of interest to disclose.

\section{REFERENCES}

1. Alkureishi MA, Lee WW, Lyons M, et al. Impact of electronic medical record use on the patient-doctor relationship and communication: a systematic review. J Gen Intern Med; doi: 10.1007/s11606-015-3582-1

2. Payne TH, Corley S, Cullen TA, Gandi TA, Harrington L, Kuperman GJ, et al. Report of the AMIA 2020 Task Force on the status and future of EMRs. J Am Med Inform Assoc. 2015;0:1-11. doi:10.1093/jamia/ocv066.

3. Fenton JJ, Jerant AF, Bertakis JD, Franks P. The cost of satisfaction: a national study of patient satisfaction, health care utilization, expenditures, and mortality. Arch Int Med; doi: 10.1001/archintrnmed2011.1662

Published online February 22, 2016 